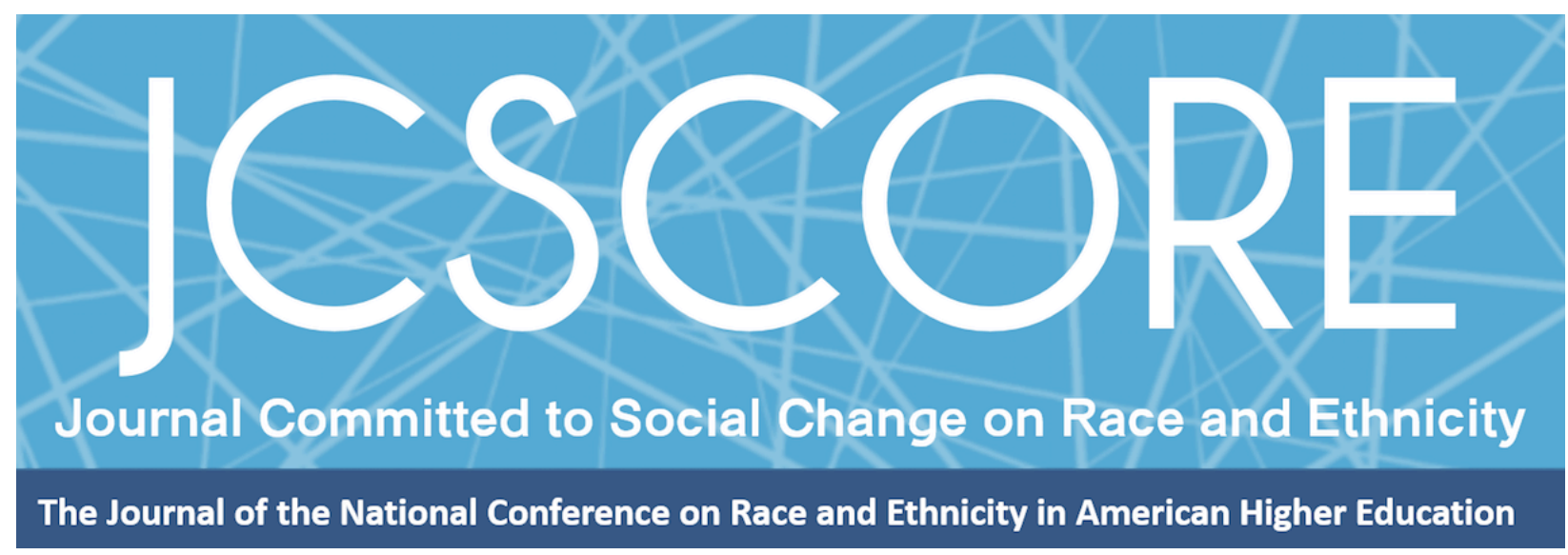

\title{
ENGAGING FILIPINX AMERICANS IN HIGHER EDUCATION TO FOSTER STUDENT SUCCESS
}

Ernest "Niki" Libarios, Jr. ${ }^{\dagger}$

University of Hawaii at Manoa*

Melissa Arriba*

Chris M. Lucas*

Kawehionalani Goto*

Roderick N. Labrador*

Journal Committed to Social Change on Race and Ethnicity

Volume 4, Issue $2 \mid 2018$

Copyright ( $\subset 2018$ Board of Regents of The University of Oklahoma on behalf of the Southwest Center for Human Relations Studies.

Permission of the Publisher is required for resale or distribution and for all derivative works, including compilations and translations. Quoting small sections of text is allowed as long as there is appropriate attribution. 


\title{
ENGAGING FILIPINX AMERICANS IN HIGHER EDUCATION TO FOSTER STUDENT SUCCESS
}

\author{
Ernest "Niki" Libarios, Jr. ${ }^{\dagger}$ \\ University of Hawaii at Manoa* \\ Melissa Arriba* \\ Chris M. Lucas* \\ Kawehionalani Goto* \\ Roderick N. Labrador*
}

Increasingly, researchers call for closer examinations of Asian Americans to counter the false, yet widely held, assumption that collectively all Asian Americans are academically successful and have similar higher education experiences. Filipinx American college students are one of the fastest growing student populations of Asian Americans in higher education. As their enrollment numbers increase, it is even more imperative to recognize how the needs of Filipinx American students as a disaggregated group, differ from other Asian American students and understand the factors that contribute to Filipinx American postsecondary success. This article focuses directly upon Filipinx American students. It explores the various higher education engagement challenges, provides a theoretical framework to better understand the Filipinx American postsecondary student experience, and offers four important institutional engagement strategies to nurture educational attainment and success.

Guided by the current population trends of Asian American students, this article challenges higher education leaders, practitioners, and policy makers to rethink and reframe their current approach in working with Filipinx American students. We utilize the term Filipinx as a way to include all genders, and to acknowledge the intersections that go beyond normative conceptualizations of gender type as a way to reinforce an

\footnotetext{
Authors' Note: In August of 2017, Dr. Ernest "Niki" Libarios, Jr. ${ }^{\dagger}$ passed away far too early in this life. Niki was a positive force in his roles with family, friends, and in his work as an educator. A local Filipino born and raised in Hawaii, Niki's passion for integrating cultural pride and education had few limits. Niki began this article with an idea and we are excited to have it be one part of his legacy going forward. We miss you dearly Niki.
} 
Journal Committed to Social Change on Race and Ethnicity | 2018

inclusive understanding of differences in Filipinx communities in both spoken word and in written text (Buenavista, 2010; Chan, 2017; Diaz, Largo \& Pino, 2018; Hanna, 2017;

Maramba \& Bonus, 2013). For this article, Filipinx serves as a general term that captures many diverse descriptors and signifies a connection to American society given that terms ending with "x" appear to have started in the United States (Salinas \& Lozano, 2017). Debate certainly exists about the use of terms ending with an " $x$," yet we believe that it best represents our population of college students (Guerrera \& Orbea, 2015). A great complexity exists regarding language, terms, and culture in relation to students claiming Filipino, Filipina, and Filipinx ancestry; and, language, terms, and cultural considerations will likely continue to evolve.

In order to unpack the important layers of complexity, this article begins with a brief historical overview of Filipinx Americans in the United States. Historical literature displays rich differences over time, including language and terminology. Next, the article discusses higher education engagement barriers faced by Filipinx American students. Then, the authors present Schlossberg's (1989) Marginality and Mattering theoretical framework for an increased understanding of the experiences of Filipinx American students. Finally, the article concludes by offering institutional engagement strategies to improve the success of Filipinx American students and shares a few collective statements about authors' positionalities.

\section{Population Trends}

The United States (U.S.) population is experiencing considerable changes in regards to its racial and ethnic composition and profile. According to the U.S. Census (2010), the Asian population category grew faster than any other race group in the 
country between 2000 and 2010. Asian, as defined by the Office of Management and Budget (U.S. Census Bureau, 2010), refers to a person having origins in any of the original peoples of the Far East, Southeast Asia, or the Indian subcontinent, including, for example, Cambodia, China, India, Japan, Korea, Malaysia, Pakistan, the Philippine Islands, Thailand, and Vietnam. Clearly, the term Asian is expansive and presents challenges when used to describe the Filipinx population.

The total number of people in the U.S. population was 308.7 million in 2010 (U.S. Census, 2010). Out of the total U.S. population, 17.3 million people, or $5.6 \%$, were Asian alone, or a combination of Asian and one or more other races. The population that identified as Asian, either alone or in combination with one or more other races, grew by $45.6 \%$ from 11.9 million in 2000 to 17.3 million in 2010 , while those who identified as Asian alone grew by $43.3 \%$ from 10.2 million to 14.7 million. Both populations grew at a faster rate than the total U.S. population, which increased by 9.7 \% from 281.4 million in 2000 to 308.7 million in 2010 (U.S. Census Bureau, 2010).

Given the trend of the increasing Asian American populations, Teranishi (2012) asserted that minority groups are likely to represent a new American majority between now and 2050. This population trend should attract not only the attention, but the actions of higher education leaders, practitioners, and policy makers as they prepare to meet the needs and understand the representation of this growing population at their campuses. If higher education leaders, practitioners, and policymakers are to serve their Asian American student populations effectively, then they must respond to this demographic shift as it will certainly impact the ethnic makeup of college campuses for the foreseeable future. One population in particular which needs attention is Filipinx 
Americans.

According to the U.S. Census (2010), Filipinx Americans are one of the fastest growing and second largest population in the nation encapsulated under the governmental term Asian American, next to Chinese Americans. Despite their growing population and complex history with the United States, Filipinx American college students are one of the least understood and researched ethnic minority groups in the country (Maramba, 2003; Museus \& Maramba, 2011). The backgrounds, strengths, and expectations of Filipinx American students in higher education represent a number of implications in relation to their educational attainment as well as added value to higher education overall.

\section{Filipinx Americans in the United States - History and Colonization}

Authors Dela Cruz and Agbayani-Siewart (2003) noted that Filipinx Americans are those individuals residing in the United States who are of Filipinx descent or whose heritage or ancestry originates from the Republic of the Philippines. They comprised about 3.4 million people, or $1.1 \%$ of the U.S. population, including those who identify as full Filipinx and part Filipinx, or a combination of Filipinx and one or more races (U.S. Census Bureau, 2010). Over the last decade, their population grew by $44.5 \%$ from 2.3 million in 2000 to 3.4 million in 2010. The greatest number of Filipinxs were located in California at $43.2 \%$. Other states with high proportions of the U.S. Filipinx population numbers were Hawaii (10\%), Illinois (4.1\%), Texas (4\%), and Washington (4\%) (U.S. Census Bureau, 2010). However, Hawaii had the highest concentration of Filipinxs in its state population (25.1\%) where they are the second largest ethnic group (U.S. Census Bureau, 2010). Although Filipinx Americans are commonly categorized nationally under 
Journal Committed to Social Change on Race and Ethnicity | 2018

the Asian American label, it is important to disaggregate them from the larger group and understand their unique and complex history with the United States particularly based on colonization.

Prior to the American colonial period, Spain colonized and ruled over the Philippines beginning in the late 1500s until the late 1800s (Espiritu, 2010; Nadal, 2013). As a legacy of Spanish colonization, the Philippines became a predominantly Catholic religion country, which influenced various cultural traditions and religious beliefs (Nadal, 2013). Immediately after the defeat of Spain in the Spanish American War in 1898, Spain ceded the Philippines to the United States. During the Spanish colonial period, Filipinxs sporadically and in small numbers migrated to various parts of what is now the United States from the sixteenth century to the late nineteenth century, before the Philippines' official incorporation as an American colonial possession (Espiritu, 2010). The U.S. beset its colonial reign on the Philippines in 1898, leaving the Philippines, yet again, a colony of an external entity.

Following the Philippine-American War, which officially lasted from 1899 to 1902 , a series of large migrations from the Philippines to the United States (and its other colonial territories like Hawaii) began and continued throughout the twentieth century (Nadal, 2013). These larger-scale migrations to the United States occurred under a set of different political economic conditions. Filipinxs initially arrived as laborers, mostly in agriculture and domestic service, and also as students (Dela Cruz \& Agbayani-Siewart, 2003; Nadal, 2013). From 1906 to 1946, a group of Filipinxs immigrated to Hawaii, working in sugar cane and pineapple plantations, to California and the southwest, laboring as migrant farmworkers, and to Alaska and the Pacific Northwest, working in 
canneries. These individuals were disproportionately undereducated males who came from poor socioeconomic backgrounds (Espiritu, 2010). A second major group of Filipinxs who immigrated to the U.S. were those who joined the U.S. Navy prior to World War I. The Immigration and Nationality Act of 1965 led to a third group of Filipinxs to the U.S. through two pathways (Buenavista, 2010; Espiritu, 2010). First, the Act awarded people visas to reunite families that had relatives of people residing in the U.S. prior to 1965. Second, the law allowed individuals with in-demand occupational skills, particularly those in the health field, to enter the U.S. labor market. The family reunification immigrants tended to be less educated and either unskilled or semiskilled, while the occupational immigrants, on the other hand, were almost entirely highly educated professionals who had obtained college degrees in the Philippines (Buenavista, 2010; Nadal, 2009; 2013). Due to the shortage of medical personnel in the U.S., large numbers of Filipinx doctors, nurses, and other health-related workers were recruited during this time to work in U.S. hospitals (Espiritu, 2010). However, it is important to note that many Filipinx immigrants who had high levels of education and who were highly skilled were often underemployed in low-wage positions due to subsequent changes in immigration laws and their immigration status as undocumented individuals (Nadal, 2009), which provides understanding and context for some Filipinxs who are seeking postsecondary educational opportunities. U.S. colonization of the Philippines initiated a long and tangled relationship, which continues to have profound and intense effects on the social, political, cultural, economic, and educational lives of Filipinx Americans today (Maramba, 2003).

These key historical events set the stage for what emerged next, namely, the 
several challenges contemporary Filipinx American postsecondary students have. We know that the populations of Filipinx/Filipina/Filipino are, have been, and are likely to continue to increase in the United States, and can subsequently expect the same for higher education institutions in the country. An expanding amount of scholarly literature offers greater details and insights regarding two periods of colonization of the Philippine Islands. Both of these influence experiences of college students and many questions remain today. Could we estimate that the second colonization by the U.S. created natural connections between the two countries for immigration? This seems reasonable (David, 2006a; 2006b; Maramba, 2008). It also oppressed the rich culture of the Philippines and provided a possible level of permission for American institutions to not have to be as concerned about the crucial need of Filipinx students' sense of belonging. We understand that we have to do more as a number of challenges exist.

\section{Challenges Facing Filipinx Americans Engagement in Higher Education}

Filipinx postsecondary students are not alone in achievement challenges for populations grouped under the broader racial category of "Asian American," "Asian Pacific Islander," "Asian Pacific American," or "Asian American and Pacific Islander." Teranishi (2012) found that Asian American and Pacific Islander (AAPI) students face a variety of challenges on college campuses in terms of engagement, including a reluctance to use support services such as academic tutoring centers, career services, and counseling; difficulty finding supportive classroom environments; a lack of culturally relevant curricular and extracurricular activities; a perception of pervasive discrimination on campus; and the challenges of resisting stereotypes of AAPI students. Similarly, a study by Bailon (2012) discovered barriers to Filipinx American college persistence 
included feelings of cultural dissonance, feelings of invisibility and marginality due to lack of representation in institution's academic and social spheres, and personal academic challenges.

Beyond the general challenges shared above and coupled with the waves of immigration noted in the history section listed previously, Filipinx students experience lived differences related to the region of the United States in which they reside (Labrador, 2015; Ocampo, 2016; Okamura, 2008). Initial immigration waves to Hawaii tended to be for agricultural work in the plantation fields; postsecondary educational attainment was less of an emphasis (Labrador, 2015; Libarios, 2013; Okamura, 2008). Today, Filipinx American college students in Hawaii remain underrepresented in the four-year institutions (Librarios, 2013). On the western coast of the continent, and to some extent on the northeast coastal area, Filipinx immigrants often transitioned to employment in medical and business professions and fewer established residences away from the coasts or Hawaii (Librarios, 2013; Ocampo, 2016). The coastal regions seemingly offered increased opportunities. This article is not intended to frame Filipinx students as being deficient or incapable; Filipinx students add a wealth of strengths, rich cultures, and other positive attributes to the American higher education system (Bachini, 2011; Maramba, 2003). Instead, it seeks to identify and briefly describe existing challenges in order to offer responsive engagement strategies and to continue the dialogue for how to best support Filipinx college students. Institutions that are able to convey to Filipinx college students that their academic work matters, that they themselves matter, create greater opportunities for success. 
Based on a review of the literature, this article presents seven types of challenges facing Filipinx American students that inhibit their engagement and pose serious challenges to their success in higher education. The seven themes are the myth of model minority, marginalization, invisibility and isolation, ethnic and racial identity, family and parent influence, financial hardships, and immigration and language barriers (Bachini, 2011; Buenavista, 2010; Libarios, 2013; Maramba, 2008; Maramba \& Bonus, 2013; Museus \& Maramba, 2011; Poon, 2014; Poon et al., 2016; Yamane, 2011-2012). While the challenges are presented as distinct sections, we recognize the intersections between them and describe their relationship throughout our analysis. These challenges reflect a comprehensive understanding of the varied Filipinx American students' contexts. Following a succinct description of each challenge and the introduction of a theoretical frame for a greater depth of analysis, we then link the frame and four suggested strategies as applicable responses to challenges outlined in the literature.

Myth of Model Minority. There is a popular image or myth of Asian American students in higher education as the "model minority," which suggests that Asian American students as a group experience high levels of universal academic, economic, and social success. Yet, the Model Minority Myth (MMM) originated with two central and rather dubious purposes: 1) "to maintain anti-Black racism . .." and 2) “. . White supremacy" (Poon et al., 2016, p. 469). Poon et al.'s (2016) review of 112 higher education research documents on Asian Americans and Pacific Islanders further outlined several areas of disconnect between the MMM and the research on AAPIs: "Simply defining the MMM as a stereotype about Asian Americans without recognizing its insidious implications for disciplining and shaming other people of color deflects 
attention away from how the myth is integral to a project of maintaining White supremacy" (p. 489) and how MMM can be a form of "deficit thinking" (p. 489). We seek to present the MMM as a multi-layered challenge for Filipinx higher education students. The MMM represents the first challenge facing Filipinx Americans in higher education.

While Asian American students are generally perceived as being academically successful in much of the related research published to date, specific populations such as Filipinx American students experience documented racial and ethnic disparities in educational attainment (Bailon, 2010; Buenavista, 2010; Libarios, 2013; Poon et al., 2016). Postsecondary Filipinx American students additionally remain understudied and underserved in American higher education settings (Museus \& Maramba, 2011). Furthermore, while research on Asian Americans in higher education exists, the clustering of Asian American and Pacific Islander groups under a single category of "Asian American" has led to major misrepresentations of particular subgroups (Bailon, 2010; Maramba, 2003; Okamura, 2008; Poon et al., 2016). In other words, the Asian American category itself conceals the diversity of its subgroups creating structural subjugation by perpetuating ethnic stereotyping in its singularity and homogeneity.

Marginalization. A second challenge illustrates that marginalization also exists (Yamane, 2011-2012). Asian American populations are often marginalized, face racial discrimination due to their language accents, and obtain careers that are less desirable to avoid rejection on the basis of language (Bachini, 2011; Libarios, 2013; Poon et al., 2016). Filipinxs are also marginalized by institutional policies that do not consider the complexities of their lives (Buenavista, Jayakumar, Misa-Escalante, \& Museus, 2009). Under color-blind policies where institutions and institutional leaders presume all 
Journal Committed to Social Change on Race and Ethnicity | 2018

students are essentially the same, Filipinxs are not necessarily recognized as firstgeneration, low-income, or historically underrepresented college students (Buenavista, 2007). Therefore, Filipinx Americans are often not eligible for institution-sponsored postsecondary access and retention programs. Suyemoto et al. (2009) asserted that some faculty and staff perceived Asian American students as a singular population at an institution of higher education, but also perceived them as relatively isolated from White students and other students of color.

Invisibility and Isolation. The third educational challenge is that Filipinx Americans in higher education continue to be understudied and their issues are often masked by their racialization as Asian Americans (Buenavista, 2010; Poon et al., 2016). The model minority myth centrally depicts Asian Americans as achieving high levels of academic and socioeconomic success in the United States through hard work, regardless of existing actual differences within and among different Asian American populations. According to Buenavista (2010), Filipinx Americans were essentially invisible under the Asian American category and experience a dichotomous racialization. This bifurcated racialization is detrimental to Filipinxs who suffer from a lack of academic and social support services from educational practitioners who overlook or are unfamiliar with their unique issues. Again, these are presented as challenges to Filipinx students, not in the sense that they are deficient in their abilities to succeed.

Furthermore, the absence of the Philippines and Filipinx Americans in school texts and other instructional materials highlights another concern. Students in many of American high schools learned about Filipinxs as peoples from distant lands, but never 
as actual members of American society with their own immigration and settlement histories (Maramba \& Bonus, 2013). Tintiangco-Cubales's (2013) study revealed that there is a significant lack of Filipinx-based curriculum, and even Filipinx teachers, which directly reflect Filipinx American experiences. Students in her study valued the need to have materials and teachers who reflected their identities regardless if the teachers were born in the United States or in the Philippines. Similarly, Bailon's (2012) study also uncovered feelings of invisibility and marginality due to lack of representation in an institution's academic and social spheres. As mentioned in the previous section, even when students gain visibility, they are subjected to marginalization and isolation. Suyemoto et al.'s (2009) study discovered that faculty and staff perceived Asian American students as isolated from White students and other students of color. Some interpreted the separation as self-segregation, while most Asian American studies faculty and staff interpreted this isolation as marginalization by their non-Asian American peers. Again, Filipinx college students ought to feel that they matter.

Ethnic and Racial Identity. Filipinx Americans encounter great difficulty in asserting their own conceptions of their ethnic identity, a fourth challenge, as well as having it accepted by other groups (Eisen, Takasaki \& Tagayuna, 2015; Ocampo, 2016; Okamura, 2008). Filipinx students may consider themselves as racially distinct and inappropriately linked with the term Asian American (David, 2006a; 2006b; Ocampo, 2016). Perhaps, in part, colonization by both Spain and the United States contributed to an identity at the individual and the country level; the Philippines history and rule compared to other Asian countries is quite different. Additionally, and according to Buenavista (2010), Filipinx youth were often subjected to imposed negative racialization 
in primary and secondary schools and as a result direct college pathways were difficult to find. Okamura (2008) asserted that ethnicity exacerbates disparities in access to resources, rewards, and privileges among ethnic groups, including Asian Americans. Suyemoto et al.'s (2009) study also uncovered that Filipinx American students experienced racial segregation on college campuses. Students from the study discussed feelings of separation between Asian American and White students as well as divisions among Asian American students from different ethnic generational backgrounds such as immigrants versus U.S.-born students. In Hawaii, for example, Okamura (2008) purported that socially and economically dominant ethnic groups Chinese Americans, Japanese Americans, and Whites - have stigmatized and subjugated other ethnic groups - such as Native Hawaiians, Filipinx Americans, and Samoans (2008). Labrador (2015) also suggested that there are intra-group differences based on immigrant generation, language, class, and place.

Although Filipinx Americans may have had similar experiences as East Asian Americans with balancing a bicultural identity and combating the multi-layered challenge of the model minority myth, their different cultural values result in unique experiences (Nadal, Pituc, Johnston \& Esparrago, 2010; Ocampo, 2016). Since Filipinx Americans are often mistaken for Hispanic/Latino Americans due to their similarity of cultural influences and physical appearance, they were subjected to the same types of negative stereotypes that Hispanic/Latinos experienced (Nadal et al., 2010; Ocampo, 2016). As a result, Filipinx Americans undergo racial and ethnic identity development that is unique and different than their East Asian American counterparts. 
Wong (2013) further illustrated Filipinx American racial identity development issues through her qualitative study of students' shared experiences. The study highlighted the related pressures to assimilate to dominant cultural norms, while maintaining connections to familial traditions and ethnic-specific cultural practices. Students in her study revealed their inner commitment to preserve and practice their family and cultural traditions, yet they struggled with their identity due to marginalization. One student explained that he was fearful of experiencing settings in which he would be pressured to forgo the values that were important to him and his family; a clear indication of identity conflict. The study showed that students form and explore racial and ethnic identity in higher education through an American social context which is influenced by familial practices and cultural traditions (Wong, 2013). The study highlighted student's identity formation which can either challenge or affirm their experiences and the processes through which they develop their identities either separated or engaged them with their campus community. Racial and ethnic identity therefore poses a multilayered and multidimensional process for how students change and evolve in their higher educational experiences (David, 2006a; 2006b). The struggle with identity for Filipinx American students perpetuated feelings of marginalization and created a lacking sense of belonging.

Family and Parental Influence. For Filipinx American students, relationships with their family and friends influence their experiences in higher education, which is the fifth challenge (Maramba, 2003). The previous statement would seem counter-intuitive, yet a couple of aspects of family and friend relationships do create challenges for Filipinx students. A study by Maramba (2003) highlighted that Filipinx Americans refrain 
from sharing positive higher education experiences at home for fear of being labeled as a "know it all" or "elitist," a coping mechanism that is an example of an isolating behavior. Filipinx American students, after postsecondary enrollment, felt limited with what they could share at home because of concerns that their parents or family members would not understand or relate to their experiences. Some described these conflicts as "switching between two worlds" thus not living a more integrated and intersectional life (Maramba, 2003). So, while other college students typically find coherence between their family and school experiences, Filipinx American students face a discontinuity between these two worlds.

Nadal (2013) noted that Filipinxs try to avoid bringing shame to themselves and their families. This value of "family shame avoidance" was also related to the reluctance Filipinxs have in seeking mental health services due to the negative stigma attached with these services, in and outside the Filipinx community (Nadal, 2013). Nadal's study also revealed that Filipinxs did not want their family or peers to know that they are struggling with any psychological problems, so they pretended that there were none. Since individuals were conditioned to represent their families well, it may be difficult for them to ask for help related to emotional, psychological, and educational issues. Furthermore, these cultural conflicts were also influenced by familial and parental values such as shame which may inhibit a Filipinx American college student's ability to productively respond to personal issues. Filipinx cultural avoidance behavior therefore involves the negotiation of racial and ethnic identities within the context of their home and college experiences. 
Journal Committed to Social Change on Race and Ethnicity | 2018

Financial Hardships. Economic hardship represents the sixth barrier and is one of the most significant challenges facing Filipinx American students in college (Tintiangco-Cubales, 2013). Financial constraints due to underemployment and other considerations often negatively impact students' participation in school. This is seen through the various employment contexts such as workers that were highly skilled, but are employed in low skill jobs, or engaged in part-time work (Buenavista, 2010; Poon, 2014; Yamane, 2011-2012).

Low socioeconomic status (SES) of Filipinx Americans coupled with family and work-related stresses limit the types of opportunities available to students, making it more difficult to fully engage in school (Libarios, 2013). A behavior known as family consolidation, in which one household is comprised of more than one nuclear family (Tintiango-Cubales, 2013), is often used as a strategy to counter socioeconomic difficulties, but could also cultivate difficult living conditions at home, including stress associated with a lack of time and ability to focus on schoolwork due to an overcrowded household, increased family obligations, and conflict arising among and between family members. Although family consolidation may serve as a strategy to enhance socioeconomic stability and mobility, it may also have a detrimental impact on educational engagement in school.

Immigration and Language Barriers. The last of the seven barriers, and on some occasions, a common challenge facing Filipinx Americans in higher education, is immigration and language barriers. Filipinxs are primarily an immigrant community and the lack of access to resources that accommodate their language differences may prevent them from being fully engaged in higher education. According to Buenavista 
(2010), although many Filipinx school-aged children were born in the United States, immigration and subsequent language barriers influenced their educational experiences, limiting access and attainment for first- and second-generation immigrant students. However, Maramba (2003) described English language proficiency as high for the average household in the Philippines so this may directly bolster their efforts in American higher education. Many Filipinx students speak English all or most of the time at school, and, in one study, nearly half reported having both Filipinx and English languages spoken equally at home (Maramba, 2003).

Furthermore, bilingual Filipinx students faced similar challenges in improving their English comprehension not necessarily because of their parents' unfamiliarity with English or the diversity of Philippine languages, but rather because of the shortage of educators fluent in their native languages who are formally trained to work with them (Buenavista, 2010). Since there are not enough educators who are adequately trained to communicate and work with Filipinx American students, language comprehension can be a barrier in school. Buenavista et al.'s (2009) study confirmed that many nonAsian American Studies faculty, the overwhelming majority of faculty on campus, felt students' lack of English proficiency was associated with communication difficulties and a lack of general academic skills. The multidimensional and intersectional nature of the seven challenges discussed above highlights the importance for engagement of Filipinxs in American higher education.

\section{Applying the Marginality and Mattering Lens}

Scholars and practitioners alike lean on various frameworks as lenses to increase understanding about issues in the field and to improve practice. A theoretical 
perspective that can be used to increase understanding of Filipinx American student engagement in higher education is Schlossberg's concepts of Marginality and Mattering (1989). At the core, the Marginality and Mattering framework pushes forward the concept of how important it is for college students to feel that they belong and that they matter on campus. We described marginality and isolation as two of the challenges Filipinx students face repeatedly. Similarly, three of the engagement strategies to be presented later serve to bolster mattering and feelings of connectedness. The framework provides a lens for understanding and additionally highlights the need for belonging on campus as a way to support racial and ethnic identity, and to mediate family and parental influences. In consideration of this lens, mattering is at the core of Filipinx student engagement. The fourth strategy we may have an indirect relationship to mattering. Schlossberg's (1989) framework was not specifically designed for application with Filipinx students, so some caution is appropriate.

Defined as the sense of not fitting in, marginality represents feelings of sadness, irritability, insecurity, and depression. For example, Filipinx Americans relate less well with the "Asian American" category because of the Philippines' colonial history. Spanish and U.S. colonialism has resulted in a historical and cultural experience more similar to Latino ethnic groups rather than other Asian American ethnic groups. According to Nadal et al. (2010), language demonstrated this point where a significant number of lexical items in the Filipino language was similar to Spanish language words and phrases. The Philippines is also different from other Asian countries as the only one to have English as one of its national languages (Nadal et al., 2010). Similarly, Filipinxs are the only Asian ethnic group to be predominantly Roman Catholic (Pew Research 
Center, 2012). As a result of these differences, the unique experiences of Filipinx Americans are often invisible within the greater "Asian American" label. Thus, Filipinx American students may experience feelings of isolation and marginalization due to cultural and linguistic differences leading to feelings of insecurity and depression, factors that hinder student engagement in higher education.

Many Filipinx Americans also consider themselves as outsiders throughout their college years, and, hence, often feel marginalized (Nadal et al., 2010; Yamane, 20112012). As Filipinx American students assume an unfamiliar role by participating in higher education, self-doubt likely increases. Coupled with feelings of marginality, selfdoubt and outsider-status expands to an even more permanent condition. Buenavista (2010) noted that Filipinx Americans face various barriers to higher education including feelings of depression, being retained at lower levels in higher education, and choosing to attend less selective colleges. She contended that the intersections of race, immigration, and socioeconomic status creates a heightened sense of marginalization.

In Hawaii, for example, institutionalized policies and practices that resulted in substantial tuition increases and the relatively higher cost of living further enhanced the likelihood of difficulties for Filipinx American postsecondary students (Libarios, 2013; Okamura, 2013). Because Filipinx Americans are overrepresented in the lower rungs of the socioeconomic ladder, their inability to meet the high costs of tuition and related fees negatively affect their enrollment and persistence in college; thus creating unequal access to higher education.

Feelings of marginality relate directly to a sense of mattering. Mattering, the belief that one matters to someone else (Schlossberg, 1989), has five aspects: 
1) Attention - the feeling that one is noticed by others,

2) Importance - the belief that one is cared about,

3) Ego Extension - the feeling that someone will empathize or sympathize with one's failures,

4) Dependence - the feeling of feeling needed, and

5) Appreciation - the feeling that one's efforts are appreciated by others. Schlossberg's five factors of mattering serve as an important construct that can disrupt, mitigate, and reduce impressions of marginality.

We highlight the five aspects of mattering in Schlossberg's (1989) framework and choose to discuss the issues of marginality and mattering in relation to the scholarly literature. We propose that the seven challenges garnered from the literature serve to effectively name and outline the construct of marginality for Filipinx students. Next, consider the five aspects on the mattering side of the framework. Perhaps we could view them somewhat as a scale where attention becomes synonymous with awareness of an issue and, at the other end, appreciation reflects much more of an interrelated and mutually positive affiliation.

The literature related to Filipinx postsecondary students has a relatively brief history of a few decades with articles, dissertations, texts, and reports. Awareness exists, as does an emphasis for how important this research is. Yet, we return to Buenavista's (2010) quotation related to potential Filipinx student that we had ". . . particularly the absence of institutional support required to make educational access a realistic opportunity for all (Gonzales, 2009; Rincon, 2008)" (p. 119). Based on the literature, realities of American higher education institutions seem not to have achieved or fully integrated the final two scale parts of dependence or appreciation to date.

\section{Engagement Strategies to Foster Student Success for Filipinx Americans}


One goal would be to have the scholarly literature about Filipinx college students contain numerous examples of intentional institutional actions across the various regions of the U.S. that are inclusive of all five aspects of Schlossberg's (1989) Marginality and Mattering framework. These examples would indicate positive conditions of sustainable success for Filipinx students. The engagement of Filipinx American students in higher education is additionally shaped by several key factors including history, culture, identity, and socioeconomic statuses. Because Filipinx American students negotiate these factors to succeed in college, they can benefit from intentional support services and programs.

We offer four services and programs in the subsequent sections to address these issues: financial aid; culturally focused organizations and spaces; parental support and family involvement; and, faculty interaction and peer mentoring programs. Previous literature in the challenges section noted how Filipinx students were reluctant to share academic and mental health issues with family, so it is crucial that institutions take on active roles of outreach. Bachini's (2011) qualitative study of Filipinx American students' perceptions of higher education revealed that finances, cultural considerations, and family, were significant factors to persistence. Furthermore, Museus and Vue (2013) suggested that parental expectations, parental involvement, teacher quality, and peer academic orientation were associated with more positive transitions to college among Asian American Pacific Islanders. Although each of the four selected strategies alone can be utilized as a first step toward improving engagement, an inclusive and multipronged engagement approach is necessary. By using a multi-pronged engagement approach, institutions could combat the multidimensional layers of challenges Filipinx 
Journal Committed to Social Change on Race and Ethnicity | 2018

students face and address these challenges in a way that will meet Filipinx students needs more successfully.

Financial Aid

Even though financial aid has a somewhat indirect relationship to Schlossberg's (1989) framework, we feel it is a critically necessary institutional strategy. American higher education is expensive for many students, and this becomes exacerbated for Filipinx students given the aforementioned discussion of financial hardships. Filipinx Americans have real financial needs tied to many factors; two being their own or their parents' undocumented status as well as prevalent underemployment (Monzon, 2013; Yamane, 2011-2012). The undocumented status alone makes it difficult for many Filipinxs to participate in the economy because they may not be legally authorized to work and thus creating an urgent financial need (Buenavista, 2009; Nadal, 2009). Buenavista (2010) noted that "With undocumented status, it was difficult to attain work for daily survival, much less money for school" (p. 119). While true that educational access is available, again, "there are several barriers to postsecondary opportunities for undocumented people, particularly the absence of institutional support to make educational access a realistic opportunity for all” (Buenavista, 2010, p. 119). Undocumented Filipinx, immigrants, and Filipinx Americans alike often face financial hardship from underemployment in the workforce. These two factors tend to permit the cycle of lower socioeconomic status and educational attainment to continue, generation after generation (Yamane, 2011-2012).

Tintiangco-Cubales (2013) also described particular cultural practices, like family consolidation, as coping mechanisms that many use to respond to a more general 
economic hardship. Although these cultural practices may serve as a possible strategy to combat financial difficulties and sustain the livelihood of Filipinx American students, such practices can also negatively affect the ways in which Filipinx American students are able to actively participate and engage in school (Buenavista, 2010). We know that educational attainment tends to lead to greater socioeconomic status, so to limit further educational gains often perpetuates limited financial standing.

Nadal et al. (2010) suggested that Filipinx American students face a number of institutional barriers as a result of their racial categorization, such as a lack of support in financial aid resources due to assumptions about their success as an Asian American model minority furthering a sense of invisibility within systems of higher education. Targeting more financial aid toward Filipinx American students could greatly expand their options with respect to how and where they enroll in American postsecondary institutions, especially with the seemingly continuous rise in tuition and fee costs. For instance, by providing additional financial aid resources, more Filipinx American students could afford to enroll in more selective four-year institutions, or attend full-time, both which would help increase their chances of completing college with a baccalaureate degree (Libarios, 2013). Better facilitating Filipinx American students' direct enrollment into four-year universities and colleges and improving how to assist those who enroll in the community colleges are vital. Since the availability of Federal Pell grants or work-study programs has not kept pace with rising tuition costs in recent years, if more financial aid grants and scholarships are awarded to students of underserved populations, such as Filipinx American students, stress due to affordability 
Journal Committed to Social Change on Race and Ethnicity | 2018

could decrease and opportunities for engagement in academic programs could increase (Libarios, 2013).

Another way to reduce the impact of financial barriers for Filipinx students is to provide workshops designed specifically for Filipinx students and their parents to learn about the financial aid process. Completing the Free Application for Student Aid (FAFSA) application process can be confusing and intimidating, but this is compounded more for Filipinx Americans and their parents with language differences and the possible lack of cultural capital or familiarity with college enrollment procedures (Rivarola, 2017). Educators and student affairs staff could assist these individuals with understanding and completing the FAFSA application at workshops and additional information could also be provided to help improve literacy about their options for paying the various costs of attendance and aid students and their families to demystify the process and better acquire and utilize the awarded financial aid. A related option could be to offer the workshops and materials in both languages given the known bilingual nature of Filipinx student households (Maramba, 2003).

\section{Culturally Focused Co-Curricular Organizations and Spaces}

The first of the strategies to relate directly to Marginality and Mattering (Schlossberg, 1989) is culturally focused co-curricular organizations and spaces. Logically, Filipinx American college students are likely aware of the needs of their Filipinx peers and can then seek more interdependence and appreciation aspects of mattering and possessing a stronger sense of belonging on campus. Campus subcultures, organizations, and physical spaces, such as for ethnic and cultural groups are primary supports related to persistence of postsecondary students, particularly 
those that identify as non-White (Bailon, 2012). According to Bachini (2011), a strong sense of cultural pride and identity among Filipinx Americans contributed positively to educational success. Creating spaces that reflect the cultural backgrounds of Filipinx American students, and are safe spaces, remain instrumental at reducing negative or unhelpful feelings. Isolation becomes less with a physical space on campus; the same space offers an alternative to a home environment where family consolidation might exist. Co-curricular groups which emphasize Filipinx students' language, norms, and values serve to support their academic success. Therefore, forming Filipinx student clubs and Filipinx or multicultural community organizations remains critically important.

Filipinx Americans students who seek to join co-curricular organizations hold multiple and simultaneous identities (Wong, 2013), claiming both Filipinx American and/or other racial and ethnic identities as well as gender, class, sexuality, religion, and place-based affiliations. It is helpful for educators, faculty, and staff to become aware of the various histories and cultural backgrounds to better serve the needs of students. Still, a positive campus environment was a key factor in establishing a culturally democratic education that is conducive to the needs of bicultural students (Maramba, 2003). To the extent that such a climate exists, Filipinx American students will continue to seek ways in which they can negotiate their identities within the college environment. Institutional stakeholders should incorporate more concepts of cultural democracy and bicultural or multicultural affirmations in order to facilitate and cultivate student participation at all levels of campus life.

Filipinx American students, while enrolled, may choose to live at home and work part-time due to cultural influences and financial hardships, so time is mostly spent 
away from campus (Tintiango-Cubales, 2013). In part, the role of family consolidation is an issue for Filipinx American students who have increased expectations and responsibilities in the home (Okamura, 2013). Institutions and educators should therefore focus on increasing interaction and culturally relevant engagement experiences in the classroom in order to maximize the time when Filipinx American students are already on campus. Developing cultural events and even perhaps academic study groups that foster campus community in a familial sense could expand the academic support system for Filipinx American students. Offering additional opportunities such as work-study employment opportunities could also increase the amount of time students spend on campus and ease financial concerns.

According to Libarios (2013), Filipinx American students in Hawaii were more likely to enter postsecondary education through the community colleges. Additionally, Filipinx American students entering through the state's community colleges and transferring to a four-year university had decreased chances of persisting to an undergraduate degree, especially for students pursuing particular types of majors, such as science, technology, engineering, and mathematics (STEM) (Libarios, 2013; Okamura, 2013). Community college campuses often lack critical human and fiscal resources as compared to the four-year institutions, creating a wider gap in how educators can increase both the amount of, and the effectiveness of, diverse student support efforts. Student affairs administrators and practitioners must also recognize the unique needs of the Filipinx American community college population that may affect the student's ability to successfully matriculate over to a four-year university or college. One example to account for both the need of the organization and the resource-needy 
community college settings would be to have a Filipinx student organization that serves students across multiple campuses in close proximity to each other. We see that example at the University of Hawaii System that has ten total institutions located in a low populated state. This organization markets events and creates resources for college students enrolled in the system. Services and support programs should also establish efficient transfer pathway programs or create a transfer advising center.

\section{Parental Support and Family Involvement}

As can often be the case, challenges and responses to those challenges can name the same item and appear to be counterintuitive. In this case, that item includes parents and family members. Parents and families are critical sources of support for Filipinx American students. Like many Asian and Pacific Islander cultures, the Filipinx family structure can be characterized as collectivistic and core to one's identity, in which the influence of the family affects the students throughout his or her college experiences (Monzon, 2013). Additionally, family support is key in fostering educational conversations and aspirations (Bailon, 2012) and there exists gender differences in the types of postsecondary discussions in Filipinx families (Espiritu 2010). Postsecondary leaders must understand that outreach to parents and families demonstrate the institutions' commitment to embracing the whole student and engaging family support that tends to be so important. In addition, this provides space in the academic environment for parents to understand and engage, allowing for increased opportunities for students to share.

A program which includes the value of family support could additionally be beneficial by allowing family members to witness first-hand the benefit of their student's 
participation in college. This strategy could result in the design of new student orientation programs. Instead of separate student and parent programs, campuses could create a program where parents and students attend the first sessions together, then gradually become split apart. This maintains the cultural value of family first and provides opportunities for institutions to better explain what the intentions of success are. A redesign of a traditional orientation program could also increase chances for Filipinx parents and family members to present their understandings and hopes about American higher education degrees to institutional staff and faculty members in order to achieve greater knowledge and to suggest other ways to alter practice. Providing early intervention through bridge and orientation programs that socializes students and families to the expectations of the academic environment could help all parties better understand the realities of academic programs.

\section{Faculty Interaction and Peer Mentoring Programs}

This engagement strategy promotes another active institutional approach and seeks to position the work of faculty and staff members as ways in which Filipinx students can feel a greater and more positive sense of belonging to the institution. Institutions can provide a range of opportunities for Filipinx American students to interact with faculty and peers. Libarios (2013) suggested a concerted effort to identify challenges Filipinx American learners face and support the educational pipeline for students through facilitation from Filipinx American faculty, administrators, and staff in the academy. Services such as advising, tutoring, and faculty mentoring programs, or peer mentoring initiatives, such as student associations, could positively impact the experiences of Filipinx American college students. To provide visible higher education 
role models for Filipinx American students, an equitable representation of Filipinx faculty, staff, and administrators which resembles the Filipinx American community in the population being served, should be a goal of higher education institutions (Libarios, 2013). We know students may isolate themselves so it will be important for them to develop strong relationships through their interactions with faculty, staff, administrators, and peers (Chan, 2017).

In addition to increased efforts of recruitment of Filipinx faculty and staff, institutions could offer employees yearly professional development workshops to help increase their knowledge and improve their sensitivity to Filipinx American experiences and cultural values and practices. This strategy, again, then mirrors the Schlossberg (1989) scale of beginning with awareness and then moving towards interdependence and celebrations of engagement. Employees can have positive interactions with students in the simplest of terms. A faculty member in the first week of a course could share the names and first meeting details of the campus cultural organizations and encourage students to attend. At a deeper level, faculty and student affairs practitioners must also participate in helping students navigate and appreciate the diversity of experiences and worldviews and integrate them into their classrooms, events, and programs. They must actively work towards dismantling the assumptions of the model minority myth, especially for Filipinx Americans, as well as other ethnic minorities, for their presumed homogeneity and foster an inclusive climate that welcomes differences among Filipinx American students with their non-Filipinx American peers.

\section{Collective Statement of Authors' Positionality}


Five authors collaborated on this article at the suggestion of one of them. While sadly, this initiating author passed away recently, the remaining four authors strove to produce an article that was both meaningful for the field and that would honor the tireless work the first author exhibited in promoting Filipinx college student success. We want the focus of the article to be upon three items: 1) the rich history of Filipinx college students, 2) the offered engagement strategies to promote their success, and 3) honoring the legacy of the first author and carrying forward his view that we should, and can, make positive contributions to the lives of Filipinx students studying in American higher education. It is therefore more problematic to share individual positionality statements; however, we can offer a few collective statements with the hopes that they provide an increased understanding of who we are and how we arrived at this stage in our research efforts.

All authors share a passion for discussing, envisioning, and actively seeking greater success for Filipinx and for all postsecondary students. Four of the five authors identify a heritage or ancestry of Filipinx, Filipina, or Filipino. We possess a range of employment types: faculty specialist, graduate student, instructional faculty, student affairs professional, and graduate assistant. We proudly state that Filipinx college students represent not just a rapidly growing population, but also a competent and capable one. The field of higher education becomes richer once we highlight and consider how Filipinx students can increase success and how we might utilize this wisdom in order to additionally assist all students. Individually, and together, we are responsible for applying knowledge and theory in practice.

\section{Conclusion}


Journal Committed to Social Change on Race and Ethnicity | 2018

Access to and persistence in higher education remains a significant challenge for many marginalized populations, like Filipinx American college students who encounter several barriers and challenges that clearly differ from other Asian American college students. The stereotype of the model minority often conceals the realities about Filipinx American students' educational needs and experiences. The aggregation of many ethnic minorities under the Asian American racial category serves to disguise the more complicated educational needs and experiences. As discussed above, existing literature demonstrates the various ways Filipinx Americans are different from their Asian American counterparts due to their colonial histories. By recognizing the uniqueness of Filipinx American students in higher education, the quality of their educational experiences will be improved by transforming relevant institutional practices.

This article describes the need for higher education leaders, administrators, practitioners, and policy makers to critically consider the ways in which institutions address barriers to the engagement of Filipinx American students. It would seem currently that Filipinx students may rely more on their own strengths and resources to achieve success as American higher education as a system has not implemented several important behaviors that are a needed foundation to impressions of mattering or belonging. If educators and practitioners are provided with the knowledge of how history, culture, and identity shape the experiences of Filipinx American students, they can begin to implement recommended strategies. While colleges and university leaders will need to determine ways to adapt their existing practices, policies, and structures required to meet the particular needs of their Filipinx American student population, the four identified recommendations provided in this article could inspire institutional change 
Journal Committed to Social Change on Race and Ethnicity | 2018

to best support and promote the engagement of Filipinx American students, and possibly other populations, in higher education that will help them thrive and succeed. 


\section{References}

Bachini, R. C. (2011). An Intercultural Perspective on Filipina/o American Persistence: Implications for College Success. 3502153 Ph.D., University of Hawaii at Manoa, United States - Hawaii. Retrieved from http://tinyurl.com/btkdtct Dissertations \& Theses @ University of Hawaii at Manoa database.

Bailon, A. M. A. (2012). Stories of persistence: Filipina/o American undergraduate students in a private, Catholic, and predominantly white university (Order No. 3548501). Available from ProQuest Dissertations \& Theses Global. (1282401876). Retrieved from http://search. proquest.com/docview/1282401876?accountid=27140

Buenavista, T. (2010). Issues Affecting U.S. Filipino Student Access to Postsecondary Education: A Critical Race Theory Perspective. Journal of Education for Students Placed at Risk (JESPAR), 15(1-2), 114-126.

Buenavista, T., Jayakumar, U., Misa-Escalante, K., \& Museus, S. D. (2009). Contextualizing Asian American education through critical race theory: An example of U.S. Pilipino college student experiences. New Directions for Institutional Research, 2009(142), 69-81.

Chan, J. (2017). Complexities of racial identity development for Asian Pacific islander Desi American (APIDA) college students. New Directions for Student Services 2017(160), 11-23.

David, E. R. J., \& Okazaki, S. (2006a). Colonial mentality: A review and recommendation for Filipino American psychology. Culture, Diversity, and Ethnic Minority Psychology, 12(1), 1-16.

David, E. R. J., \& Okazaki, S. (2006b). The colonial mentality scale (CMS) for Filipino Americans: Scale construction and psychological implications. Journal of Counseling Psychology, 53(2), 241-252.

Dela Cruz, M., \& Agbayani-Siewart, P. (2003). Asian-nation: The landscape of Asian America. Choice Reviews Online, 40(05), 40-2851.

Diaz, R., Largo, M. \& Pino, F. (Eds.). 2018. Diasporic intimacies: Queen Filipinos and Canadian imaginaries. Evanston, Illinois: Northwestern University Press.

Eisen, D. B., Takasaki, K., \& Tagayuna, A. (2015). Am I really Filipino?: The unintended consequences of Filipino language and culture courses in Hawaii. Journal Committed to Social Change on Race and Ethnicity, 1(2), 25-53.

Espiritu, Y. (2010). Filipino American Lives. Temple University Press.

Fajardo, D. E. (2002). Retention factors of Filipino students at Hawaii community colleges (Order No. 3073773). Available from ProQuest Dissertations \& Theses Global. (305514477). Retrieved from http://search.proquest.com/docview/305514477? ?accountid=27140

Guerrera, G., \& Orbea, G. (2015, November 19). The argument against the use of the term "Latinx". The Phoenix. Retrieved from http://swarthmorephoenix.com/2015/11/19the_argument-against-the-use-of-theterm-latinx/

Hanna, K. B. (2017). A call to healing: Transphobia, homophobia, and historical trauma in Filipilina/o/x American activist organizations. Hypatia 32(3), 696-714.

Doi:10.111/hypa.12342

Labrador, R. N. (2015). Building Filipino Hawaii. Urbana, IL: University of Illinois Press. 
Libarios, E. N. D., Jr. (2013). Social stratification and higher education outcomes: The case of Filipinos in Hawai i (Order No. 3577236). Available from ProQuest Dissertations \& Theses Global. (1468460394). Retrieved from http://search.proquest.com/docview/1468460394?accountid=27140

Maramba, D. C. (2003). Negotiating structures of higher education and bicultural identity through the voices of Filipino/a-American college students (Order No. 3086749). Available from ProQuest Dissertations \& Theses Global. (305254102). Retrieved from http://search. proquest.com/docview/305254102?accountid $=27140$

Maramba, D. C. (2008). Immigrant Families and the College Experience: Perspectives of Filipina Americans. (Author abstract) (Report). Journal of College Student Development, Annual, 2008.

Maramba, D., \& Bonus, R. (2013). The "other" students: Filipino Americans, education, and power. Charlotte, NC.

Monzon, R. I. (2013). Collective Self-Esteem and Perceptions of Family and Campus Environments among Filipino American College Students. In D. Maramba \& R. Bonus (Eds). The "other" students: Filipino Americans, education, and power (pp. 237-258). Charlotte, NC: Information Age Publishing.

Museus, S. D., \& Maramba, D. C. (2011). The impact of culture on Filipino American students' sense of belonging. The Review of Higher Education, 34(2), 231-258.

Museus, S. D., \& Vue, R. (2013). Socioeconomic status and Asian American and Pacific Islander students' transition to college: A structural equation modeling analysis. The Review of Higher Education, 37(1), 45-76. The Johns Hopkins University Press.

Museus, S. D., Maramba, D. C., \& Teranishi, R. T. (2013). The misrepresented minority: New insights on Asian Americans and Pacific Islanders, and the implications for higher education. Sterling, VA: Stylus.

Nadal, K. L. (2009). Filipino American psychology: A handbook of theory, research, and clinical practice. Bloomington, IN: AuthorHouse.

Nadal, K. L., Pituc, S. T., Johnston, M. P., \& Esparrago, T. (2010). Overcoming the Model Minority Myth: Experiences of Filipino American Graduate Students. Journal of College Student Development, 51(6), 694-706. The Johns Hopkins University Press.

Nadal, K. L. (2013). Counseling Filipino American College Students: Promoting Identity Development, Optimal Mental Health, and Academic Success. In D. Maramba, \& R. Bonus (Eds), The "other" students: Filipino Americans, education, and power (pp. 103-119). Charlotte, NC: Information Age Pubilshing.

Ocampo, A. C. (2016). The Latinos of Asia: How Filipino Americans break the rules of race. Stanford, CA: Stanford University Press.

Okamura, J. (2008). Ethnicity and inequality in Hawaii. Philadelphia: Temple University Press.

Okamura, J. (2013). Filipino American Access to Public Higher Education in California and Hawaii. In D. Maramba, \& R., Bonus (Eds), The "other" students: Filipino Americans, education, and power (pp. 213-235.) Charlotte, NC: Information Age Publishing. 
Pew Research Center (2012). Asian Americans: A Mosaic of Faiths. Retrieved from http://www.pewforum.org/2012/07/19/asian-americans-a-mosaic-of-faithsoverview/

Poon, O. (2014). "The land of opportunity doesn't apply to everyone": The immigrant experience, race, and Asian American career choices. Journal of College Student Development, 55(6), 499-514.

Poon, O., Squire, D., Kodama, C., Byrd, A., Chan, J., Manzano, L., Furr, S., \& Bishundat, D. (2016). A critical review of the Model Minority Myth in selected literature on Asian Americans and Pacific Islanders in higher education. Review of Higher Education, 86(2), 469-502.

Quaye, S. J., \& Harper, S. R. (Eds). (2015). Student engagement in higher education: Theoretical perspectives and practical approaches for diverse populations $\left(2^{\text {nd }}\right.$ Ed.). New York: Routledge.

Rivarola, A. R. R. (2017). "Undocumented” ways of navigating complex sociopolitical realities in higher education: A critical race counterstory. Journal of Critical Scholarship on Higher Education and Student Affairs, 3(1), 101-125.

Salinas, C. Jr., \& Lozano, A. (2017). Mapping and recontextualizing the evolution of the term Latinx: An environmental scanning in higher education. Journal of Latinos and Education, 1-14. DOI: 10.1080/15348431.2017..1390464

Schlossberg, N. K. (1989). Mattering and marginality: Key issues in building community. In D.C. Roberts (Ed.), Designing campus activities to foster a sense of community. New Directions for Student Services (no. 48, pp. 5-15). San Francisco, CA: Jossey-Bass.

Suyemoto, K., Kim, G., Tanabe, M., Tawa, J., Day, S., \& Museus, S. D. (2009). Challenging the model minority myth: Engaging Asian American students in research on Asian American college student experiences. New Directions for Institutional Research, 2009(142), 41-55.

Strayhorn, T. L. (2012). College students' sense of belonging: A key to educational success for all students. New York: Routledge.

Teranishi, R., Behringer, L., Grey, E., Parker, T., \& Museus, S. D. (2009). Critical race theory and research on Asian Americans and Pacific Islanders in higher education. New Directions for Institutional Research, 2009(142), 57-68.

Teranishi, R. T. (2012). Asian American and Pacific Islander students and the institutions that serve them. Change, 44(2), 16-22.

Tintiango-Cubales, A. (2013). Struggling to survive: Poverty, violence, and invisibility in the lives of urban Filipina/o American youth. In D. Maramba, D. \& R. Bonus, R. (Eds), The "other" students: Filipino Americans, education, and power (pp. 123143). Charlotte, NC: Information Age Publishing.

U.S. Census Bureau, (2010). The Asian Population: 2010. Retrieved from http://www.census.gov/prod/cen2010/briefs/c2010br-11.pdf

Wong, A. (2013). Racial identity construction among Chinese American and Filipino American undergraduates. In S. D. Museus, D. C. Maramba, \& R. T. Teranishi (Eds), The misrepresented minority: New insights on Asian Americans and Pacific Islanders, and the implications for higher education (pp. 86-106). Sterling, VA: Stylus. 
Journal Committed to Social Change on Race and Ethnicity | 2018

Yamane, L. (2011-2012). Asian Americans, glass ceilings, and PhDs. Harvard Journal of Asian American Policy Review, 22(2012-2012), 29-41. 